Proceedings

\title{
Hybrid Micro Electro Mechanical Sensor Based on Graphene Oxide/Polyvinyl Alcohol for Humidity Measurements ${ }^{\dagger}$
}

\author{
Carlo Trigona ${ }^{1, *}$, Ammar Al-Hamry ${ }^{2}$, Olfa Kanoun ${ }^{2}$ and Salvatore Baglio ${ }^{1}$ \\ 1 DIEEI, Dipartimento di Ingegneria Elettrica Elettronica e Informatica, University of Catania, 95125 Catania, \\ Italy \\ 2 Professorship of Measurement and Sensor Technology, Chemnitz University of Technology, \\ ReichenhainerStraße 70, 09126 Chemnitz, Germany; ammar.al-hamry@etit.tu-chemnitz.de (A.A.-H.); \\ olfa.kanoun@etit.tu-chemnitz.de (O.K.) \\ * Correspondence: carlo.trigona@dieei.unict.it.com; Tel.: +39-095-7382-2301 \\ + Presented at the Eurosensors 2018 Conference, Graz, Austria, 9-12 September 2018. \\ Published: 19 December 2018
}

\begin{abstract}
In this paper, we present a redundant micromachined sensor based on Bulk and Etch. Silicon-on-Insulator (BESOI) process for measurements of relative humidity (RH) by using Graphene-Oxide/Polyvinyl-Alcohol (GO/PVA) composite. The microsensor is a mechanical oscillator composed of a proof mass with multilayer of nanomaterials (GO/PVA) and suspended by four crab leg springs. The realized redundant approach concerns the possibility to use different readout strategies in order to estimate the same measurand: $\mathrm{RH}$. This is an intriguing solution to realize a "robust measurement system", with multiple outputs by using the GO/PVA as functional material. In presence of RH variation: (1) it changes its mass and; as consequence; a variation of the natural frequency of the oscillator can be observed in the frequency domain; (2) it also varies the conductivity which can be measured by using two integrated electrodes. The sensor has been designed; studied; modeled and experimental results demonstrate the effectiveness of our implementation.
\end{abstract}

Keywords: redundant measurements; hybrid sensor; nanomaterial; GO/PVA composite; humidity sensor; micromachined sensor

\section{Introduction}

Recently, an extensive research has been conducted on the design and conception of robust solutions for measurement systems and redundant strategies mainly based on multiple sensors and repeated sensing elements [1]. The main purposes of redundant approaches presented in literature are to provide highly reliable and accurate measurements [2].

In this context the interest of the scientific community is highly felt in macro scale but also in small and integrated scale sensors [3]. The mentioned redundant approaches regard the use of several/multiple sensors to compare the measure. This implies a considerable number of devices/nodes to be used. Humidity sensors have earned considerable attention due to the increasing demand for moisture monitoring in semiconductor industries, automobile industries, living environments and domestic applications [4]. Humidity sensors are realized considering different readouts such as capacitive, piezoresistive, optical, piezoelectric and quartz-based transduction, optical and glass-fiber architectures [5]. It is worth noting that, polymer, PANI/PVA [6] carbon nanotubes [7] or graphene oxide [8,9] based humidity sensors are already proposed. Polymer nanocomposites could bring low-cost processing, both resistive and capacitive response, 
and a widerange of humidity sensing. Polymer nanocomposites having filler at least one dimension in nanoscale, brought considerable attention for investigation, since Kojima usuki et al. [10] at first reported nylon/clay nanocomposites. They are often recognized for tuned thermal, electrical, and mechanical properties different from their parent materials. The functional groups of GO add the dispersibility inside the PVA matrix or other polar aqueous media. Kashyap et al. [11] found $150 \%$ elastic modulus increment after $0.3 \mathrm{wt} \%$ loading in PVA. PVA, on the other hand, is a widely used thermoplastic, water soluble, nontoxic polymer [12].

The approach here proposed is based on a single device to measure RH by using different readout strategies. It is based on the adoption of a GO/PVA composite [13] used as functional material, and deposited over a BESOI-based microsensor [14,15], operating as mechanical oscillator and designed through MEMSPRO. In the presence of an increment of RH this material is able to increase its inertial mass and, at the same time, it is able to increase its conductivity. At the moment, this is the first solution of redundant sensor realized in integrated scale and based on GO/PVA used as functional layer.

\section{Materials and Methods}

Aqueous GO solution of $0.5 \mathrm{wt} \%$ (flake size 0.5 to 5 microns) was purchased from graphenesupermarket. PVA powder was added into water to make $4 \mathrm{wt} \%$ of aqueous solution. PVA solution was kept at $90{ }^{\circ} \mathrm{C}$ for $2 \mathrm{~h}$ along with magnetic stirring for achieving good solubilibility. Later, GO solution was poured into the PVA polymerand stirred for $30 \mathrm{~min}$ and sonicated for 10 more minutes, (see Figure 1a).

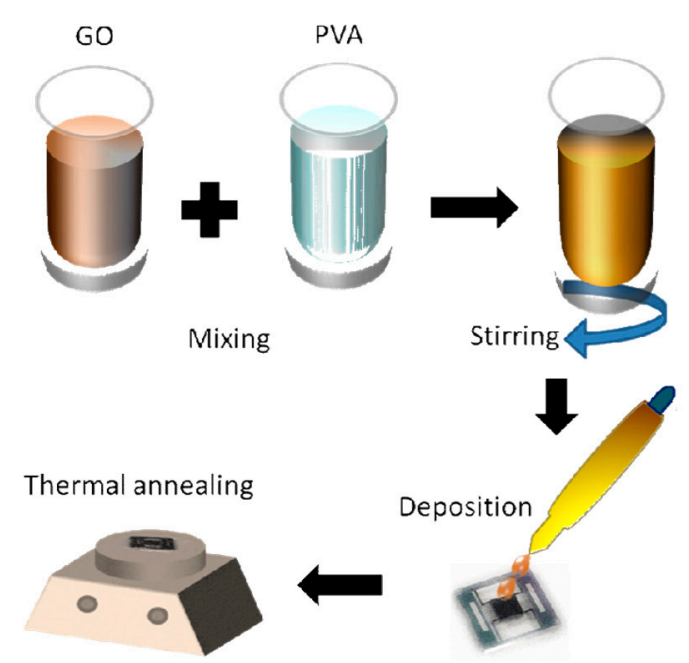

(a)

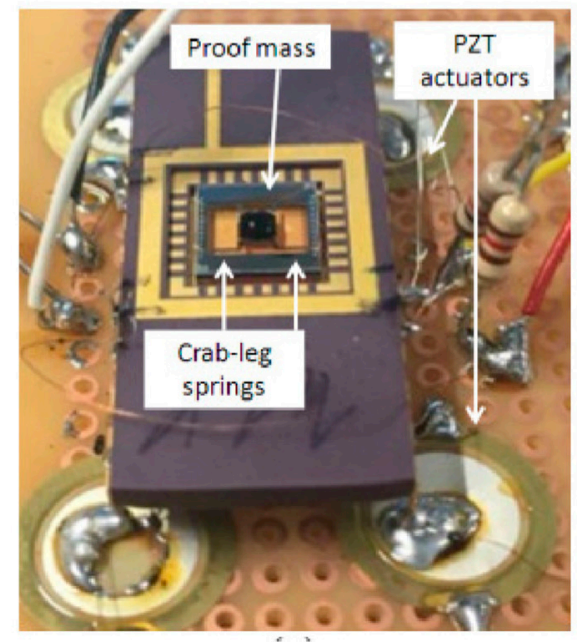

(b)

Figure 1. Sensor fabrication: (a) GO/PVA composites preparation by solution mixing and deposition on the micromachined sensor and (b) realized microsensor and four PZT elements used to move the device.

The micromachined sensor is composed of four crab-leg beams with a suspended mass of 1600 $\mu \mathrm{m} \times 1600 \mu \mathrm{m} \times 467 \mu \mathrm{m}$ of silicon and $1 \mu \mathrm{m}$ of metal plate used to contact the GO/PVA located on the proof mass, (see Figure 1b). In that, an amount of $10 \mu \mathrm{m}$ was casted on the suspended silicon and dried overnight. In order to increase the conductivity of the GO/PVA sensor, the sensor was annealed at $300{ }^{\circ} \mathrm{C}$. A natural frequency of $\sim 350 \mathrm{~Hz}$ was estimated by using the heterogeneous beam theory $[14,15]$. In order to validate the readout based on the variation of the natural frequency of the mechanical oscillator as function of the variation of $\mathrm{RH}$, two integrated strain gauges were connected in a Wheatstone bridge and the output was acquired by using an oscilloscope (LeCroywaverunner 6050) as shown in Figure 2. Furthermore, a sourcemeter (Keithley-2636) was used to measure the variation of resistance of the functional material connected by using two integrated electrodes. 


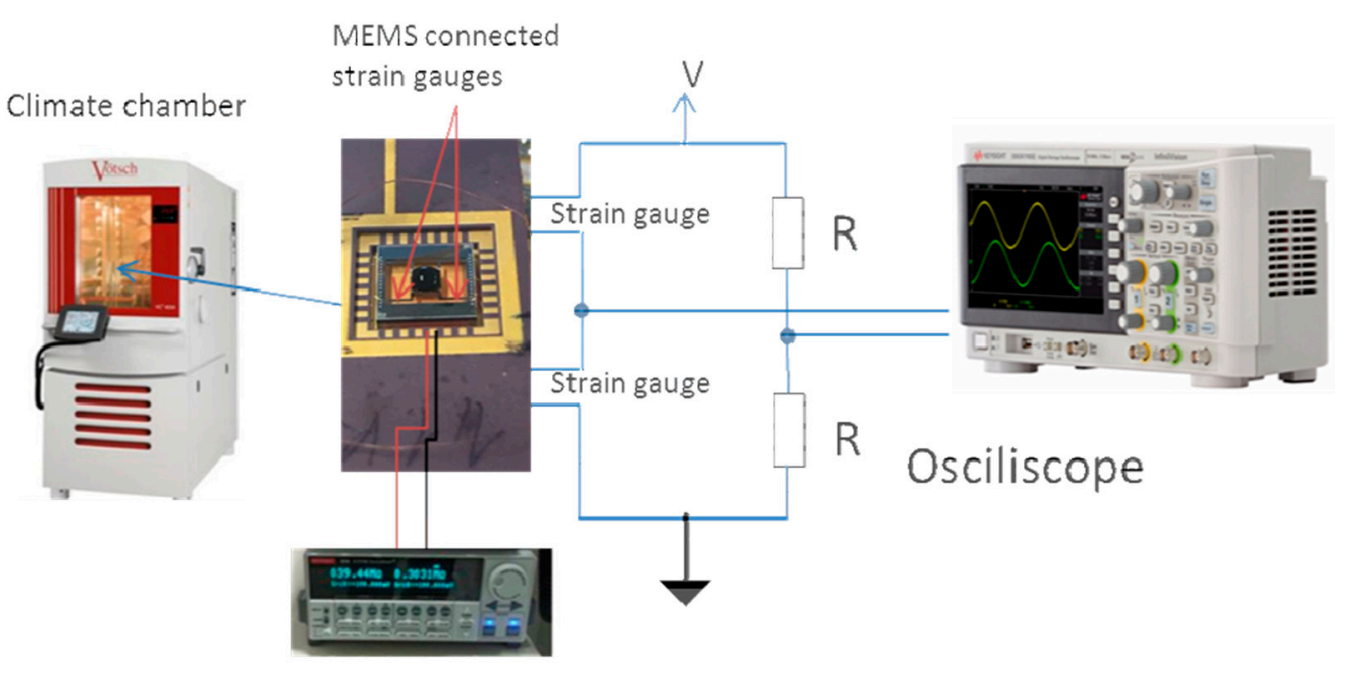

sourcemeter

Figure 2. Experimental setup composed of a humidity chamber to control the humidity and temperature applied to the MEMS. The output was registered by a sourcemeter and an oscilloscope to obtain the resistance of the GO/PVA film and the oscillation frequency of the bridge.

\section{Results and discussion}

Figure 3a shows the FFT of the output of the bridge for a fixed mechanical frequency $(350 \mathrm{~Hz})$ imposed through four piezoelectric actuators. The result shows the effect of the spike for several $\mathrm{RH}$ amplitudes (from $20 \%$ to $80 \%$ ). A decrement can be observed as consequence of the movement of the natural frequency of the oscillator. It is worth to mention that, in order to validate the resonance, a variation in terms of excitation frequency has been impressed and, as shown in Figure $3 \mathrm{~b}$, a maximum spike can be observed in resonant condition. Figure 4 shows the two outputs: the bridge (variance) and the measured resistance of the GO/PVA for several values of humidity. As it can be observed the sensor is capable to measure the target through the frequency domain and the resistance domain by using the properties of the GO/PVA. A sensitivity of $\sim-12 \mathrm{k} \Omega / \mathrm{RH} \%$ and $\sim 0.1$ $\mathrm{Hz} / \mathrm{RH} \%$ have been estimated in the resistance and frequency domain, respectively. Furthermore, a resolution of $\sim 1.8 \% \mathrm{RH}$ has been experimentally estimated.

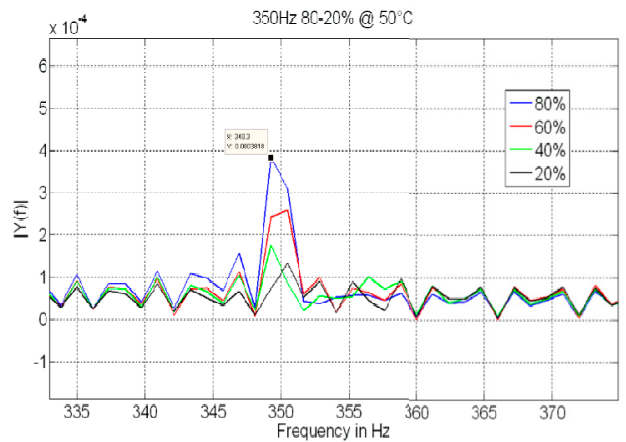

(a)

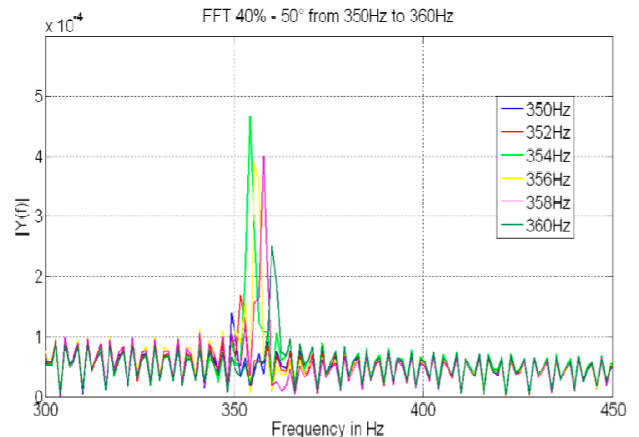

(b)

Figure 3. (a) FFT of the output of the bridge at $350 \mathrm{~Hz}\left(50^{\circ} \mathrm{C}\right)$; (b) analysis around the mechanical resonance (at $40 \%, 50^{\circ} \mathrm{C}$ ). 


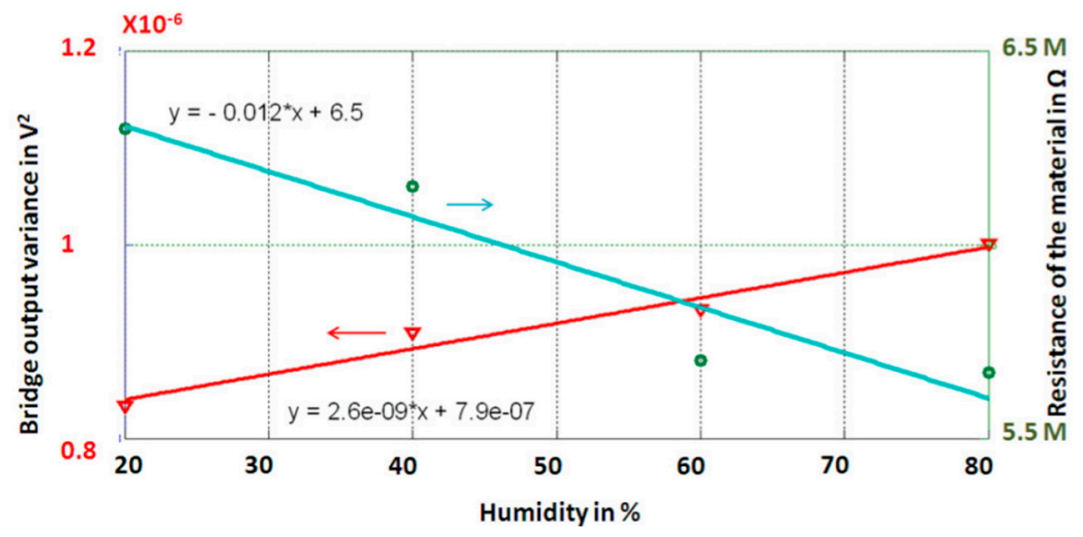

Figure 4. Validation of the redundant principle. It is possible to measure the humidity by using the variation of the output bridge (for a fixed mechanical excitation frequency) and the variation of the resistance of the GO/PVA.

\section{Summary and Conclusions}

In this work a hybrid integrated sensor based on Graphene Oxide/Polyvinyl Alcohol has been used for measurements of relative humidity. The approach here pursued regards the possibility to perform the measurements by using multiple readouts with analyses in the frequency and conductivity domains. In particular a sensitivity of about $0.1 \mathrm{~Hz} / \mathrm{RH} \%$ and about $-12 \mathrm{k} \Omega / \mathrm{RH} \%$ have been estimated. The resolution of the sensors corresponds to $\sim 1.8 \% \mathrm{RH}$. Further research will be devoted to demonstrate the effectiveness of the redundant approach to improve immunity to interfering signals.

Acknowledgments: The authors would like to thank the German Academic Exchange Service (DAAD) for funding (funding \#57314019, Research Stays for University Academics and Scientists, 2017; applicant Carlo Trigona).

\section{References}

1. Lorussi, F.; Rocchia, W.; Scilingo, E.P.; Tognetti, A.; Rossi, D.D. Wearable, redundant fabric-based sensor arrays for reconstruction of body segment posture. IEEE Sens. J.2004, 4, 807-818, doi:10.1109/JSEN.2004.837498.

2. Picas, R.; Zaragoza, J.; Pou, J.; Ceballos, S. Reliable modular multilevel converter fault detection with redundant voltage sensor. IEEE Trans. Power Electron. 2017, 32, 39-51, doi:10.1109/TPEL.2016.2526684.

3. Rogne, R.H.; Bryne, T.H.; Fossen, T.I.; Johansen, T.A. Redundant MEMS-Based Inertial Navigation Using Nonlinear Observers. J. Dyn. Syst. Meas. Control 2018, 140, 071001, doi:10.1115/1.4038647.

4. Chen, Z.; Lu, C. Humidity Sensors: A Review of Materials and Mechanisms. Sens. Lett. 2005, 3, 274-295, doi:10.1166/sl.2005.045.

5. Kolpakov, S.A.; Gordon, N.T.; Mou, C.; Zhou, K. Toward a New Generation of Photonic Humidity Sensors. Sensors 2014, 14, 3986-4013, doi:10.3390/s140303986.

6. Yang, M.Z.; Dai, C.L.; Lin, W.Y. Fabrication and characterization of polyaniline/PVA humidity microsensors. Sensors 2011, 11, 8143-8151, doi:10.3390/s110808143.

7. Fei, T.; Jiang, K.; Jiang, F.; Mu, R.; Zhang, T. Humidity switching properties of sensors based on multiwalled carbon nanotubes/polyvinyl alcohol composite films. J. Appl. Polym. Sci. 2014, 131, 1-7, doi:10.1002/APP.39726.

8. Borini, S.; White, R.; Wei, D.; Astley, M.; Haque, S.; Spigone, E.; Harris, N.; Kivioja, J.; Ryhanen, T. Ultrafast graphene oxide humidity sensors. ACS Nano 2013, 7, 11166-11173, doi:10.1021/nn404889b.

9. Bi, H.; Yin, K.; Xie, X.; Ji, J.; Wan, S.; Sun, L.; Terrones, M.X.; Dresselhaus, M.S. Ultrahigh humidity sensitivity of graphene oxide. Sci. Rep. 2013, 3, 1-7, doi:10.1038/srep02714.

10. Usuki, A.; Kojima, Y.; Kawasumi, M.; Okada, A.; Fukushima, Y.; Kurauchi, T.; Kamigaito, O. Synthesis of nylon 6-clay hybrid. J. Mater. Res. 1993, 8, 1179-1184, doi:10.1002/pola.1993.080310418. 
11. Kashyap, S.; Pratihar, S.K.; Behera, S.K. Strong and ductile graphene oxide reinforced PVA nanocomposites. J. Alloys Compd. 2016, 5, 254-260, doi:10.1016/j.jallcom.2016.05.162.

12. Potts, J.R.; Dreyer, D.R.; Bielawski, C.W.; Ruoff, R.S. Graphene-based polymer nanocomposites. Polymer 2011, 52, 5-25, doi:10.1016/j.polymer.2010.11.042.

13. Al-Hamry, A.; Prosenjit, K.; Torres, R.V.; Müller, C.; Kanoun, O. Electrochemical impedance spectroscopy of graphene oxide/polyvinyl alcohol composites. In Proceedings of the International Workshop on Impedance Spectroscopy, Chemnitz, Germany, 26-28 September 2016.

14. Trigona, C.; Ando, B.; Baglio, S. Design, fabrication, and characterization of BESOI-accelerometer exploiting photonic band gap materials. IEEE Trans. Instrum. Meas. 2014, 63, 702-710, doi:10.1109/TIM.2013.2277534.

15. Andò, B.; Baglio, S.; Baù, M.; Ferrari, V.; Sardini, E.; Savalli, N.; Trigona, C. Numerical and experimental investigation on contactless resonant sensors. Sens. Actuators A Phys. 2010, 162, 329-335, doi:10.1016/j.sna.2010.04.009.

(C) 2018 by the authors; Licensee MDPI, Basel, Switzerland. This article is an open access article distributed under the terms and conditions of the Creative Commons Attribution (CC BY) license (http://creativecommons.org/licenses/by/4.0/). 